\title{
Systemic capital requirements ${ }^{1}$
}

\author{
Lewis Webber and Matthew Willison ${ }^{2}$
}

\section{Introduction}

Banking regulation has historically focused on making a detailed assessment of risk at the level of individual banks' balance sheets. But, in an interconnected system, banks that appear sufficiently healthy when viewed individually may collectively present a material threat to the solvency of the system as a whole. First, there may be similarities between banks' asset exposures that generate a tendency for banks' solvency positions to deteriorate and improve together. This can leave the system vulnerable to common shocks to the macroeconomy or to capital markets. Second, losses at an individual bank that are sufficient to cause it to default may trigger contagious failures of other banks in the system if they have extended it loans. Such contagious failures could, in turn, trigger further rounds - or cascades - of contagious defaults in the banking system. System-wide losses could then far exceed the size of the initial shock.

Vulnerabilities of the system as a whole that cannot be identified by focusing narrowly on the health of individual banks suggest that a change in the way that risks to the banking system are assessed and prudential requirements for banks are calibrated could be beneficial. This paper describes a system-wide risk management approach to deriving capital requirements for banks that reflect the impact their failure would have on the wider banking system and the likelihood of contagious losses occurring.

At the centre of the approach is the policymaker's optimisation problem. The policymaker is assumed to be interested in ensuring that the probability of banking system insolvency over a given time horizon is less than a chosen target level. This reflects the policymaker's systemic risk tolerance. The target could, of course, be achieved in all states of the world by setting very high systemic capital requirements. But the policymaker may also want to limit the potential inefficiency costs associated with regulatory capital requirements. In particular, if equity capital is more expensive than debt because of market frictions, higher capital requirements could, for example, increase the cost of bank lending to non-bank borrowers in the wider economy. The possible trade-off between financial stability and financial efficiency motivates a constrained optimisation problem, where a policymaker seeks to identify capital requirements for individual banks that keep to a minimum the total level of capital in the banking system overall, subject to meeting their chosen systemic risk target. The solution of the constrained optimisation problem is a unique level of capital in the banking system and its distribution across banks.

In this paper, the constrained optimisation problem faced by the systemic policymaker is combined with a structural model of the banking system to determine risk-based systemic capital requirements for individual banks. The evolution of banks' balance sheets and the manner in which interbank (or "network") exposures between firms are cleared follow Elsinger et al (2006), in the spirit of Merton (1974). This captures two drivers of systemic risk: (i) the correlations between banks' assets that may lead to multiple banks becoming

1 This paper is an abridged version of L Webber and M Willison, "Systemic capital requirements", Bank of England Working Paper 436, 2011.

2 Bank of England. 
fundamentally insolvent simultaneously; and (ii) the potential for contagious failures to occur, as losses from fundamentally insolvent banks are transmitted and amplified in the wider system via defaults on interbank obligations.

The paper assumes a very specific form of an objective function that a systemic policymaker could adopt, centred solely on resilience. A broader modelling framework and objective function might also include measures of cyclical imbalances in the economy including, for example, deviations of bank credit availability from a measure of equilibrium. These considerations are beyond the scope of this paper. Moreover, the modelling choices in the paper reflect a trade-off between realism (complexity) and pragmatism (simplicity) in the description of credit risks facing an interconnected banking system. As such, the primary focus of the paper is to obtain general insights into the properties of risk-based systemic capital requirements, rather than to calibrate precise nominal amounts that may be required to achieve particular risk targets in practice.

The paper is structured as follows. First we outline the details of the model and the policymaker's optimisation problem. We then set out the calibration of the model and the iterative process used by the policymaker to determine banks' systemic capital requirements - namely, the minimum configuration of capital across banks consistent with a particular measure and target for system-wide credit risk. Finally we present illustrative results for systemic capital requirements and comparative static exercises.

\section{Modelling systemic solvency risk}

This paper uses the Merton-style structural credit risk model described by Elsinger et al (2006) to quantify risks to the solvency of an interconnected banking system. The model can be thought of as a panel of correlated Merton (1974) balance sheet models, jointly estimated using observed bank equity returns, and combined with a network of interbank exposures that is cleared using the algorithm described by Eisenberg and Noe (2001). Figure 1 illustrates the broad setup of the model used to quantify systemic risk in this paper (inside the hatched border) and the type of comparative static exercises and numerical optimisations that can be performed using the model (blue). The asset value dynamics of the combined balance sheet model can be used to produce the distribution of asset shortfalls below promised debt liabilities for the system as a whole - which are hereafter called system losses.

Figure 1

\section{A general balance sheet model for quantifying systemic credit risk ${ }^{(a)}$}

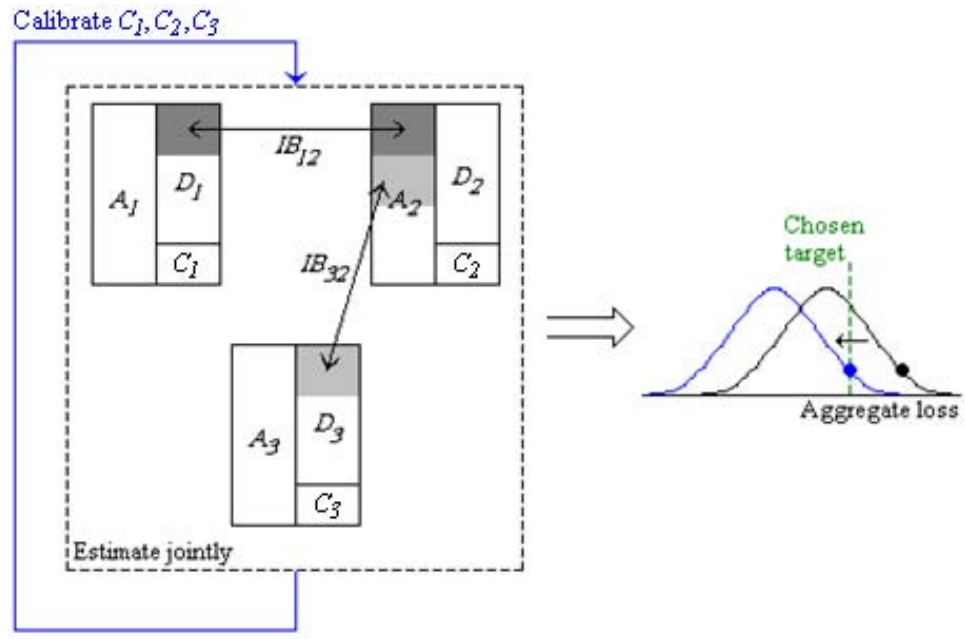

(a) $A, D$ and $C$ refer to assets, debt and capital, respectively. 
Each bank $\{i\}_{i=1,2, \ldots, n}$ holds assets outside of the banking system of $A_{i}^{0}$ and is assumed to have a single issue of zero-coupon debt outstanding to non-banks with a face value of $D_{i}^{0}$ that falls due for repayment at time $\tau_{i}=\tau$. In addition, each bank $\{i\}_{i=1,2, \ldots, n}$ may have an aggregate interbank asset against the other banks in the system of $A_{i}^{I}$ and an aggregate interbank liability of $D_{i}^{I}$. These inter-bank exposures are captured in an inter-bank matrix $M$. Like debt to non-banks, interbank debt is also assumed to have a maturity $\tau_{i}=\tau$. Banks are also partly financed by equity: bank $i$ has a capital ratio $c_{i}=\frac{C_{i}}{A_{i}}$, where $C_{i}$ is the nominal value of capital issued by a bank. Total system assets are given by $A \equiv \sum_{i} A_{i}=\sum_{i}\left(A_{i}^{0}+A_{i}^{I}\right)$ and the total face value of debt liabilities is $D \equiv \sum_{i} D_{i}=\sum_{i}\left(D_{i}^{0}+D_{i}^{I}\right)$.

Each bank's assets $A_{i}$ evolve according to a geometric Brownian motion with ex ante fixed coefficients $\left\{\mu_{i}, \sigma_{i}\right\}$ :

$\frac{d A_{i}}{A_{i}}=\mu_{i} d t+\sigma_{i} d W_{i}^{P}$ for $i=1,2, \ldots, n$

and where shocks may be correlated across banks, $d W_{i}^{P} d W_{j}^{P}=\rho_{i j} d t \neq 0$.

Based on these correlated asset dynamics, the solvency positions of banks $\{i\}_{i=1,2, \ldots, n}$ are checked at date $\tau_{i}=\tau$. There are two types of default in the model, labelled "fundamental" and "contagious". If, after simulating forward the above diffusion process, the assets of any given bank, $X$, are below its (fixed) debt liabilities at time $\tau_{X}=\tau$, bank $X$ is declared fundamentally insolvent. In this case, its loss-given-default is endogenously given by the difference between the level of assets at the point at which solvency is assessed and the face value of its debt falling due. But losses for the system do not end here. The fundamental default of bank $X$ triggers losses for other banks in the network that have extended it interbank loans. In some cases, clearing of the interbank network $M$ may result in a second bank, $Y$, defaulting - even though it may be above the solvency threshold if it had not made this loss on its interbank exposure to bank $X$. This represents a contagious failure for bank $Y$. In this case, the assets of bank $Y$ are marked down from the level reached under the diffusion process in equation (1) by an exogenously-chosen contagious bankruptcy cost of $10 \%$ (based on James (1991)). The interbank positions of other banks in the network are then re-evaluated. This process is repeated until there are no further rounds of contagious default in the banking network. It presents a mechanism by which losses initially borne by one bank can be transmitted and amplified through an interconnected banking system. Denoting the value of each banks' assets after network clearing by $\widetilde{A}_{i}$, total losses in the banking system at debt maturity $\tau_{i}=\tau$ are thus given by:

$L=\sum_{i}\left(D_{i}-\tilde{A}_{i}(\tau)\right)$

\section{Policymaker's optimisation problem}

If capital is more expensive than debt, the efficiency of the banking system is a decreasing function of the total capital held across banks. Capital could be more expensive than debt for 
various reasons, including because of principal agent problems between managers and shareholders (Jensen (1986); Jensen and Meckling (1976)) or because of information asymmetries between insiders and external investors (Myers and Majluf (1984)). A policymaker interested in mitigating systemic risk, however defined, while limiting inefficiency in the banking system might therefore seek to achieve a chosen systemic risk objective for the lowest compatible level of capital in aggregate. In this paper, the systemic risk objective is defined in terms of a target for the location of the $z^{\text {th }}$ percentile of the distribution of system losses relative to promised debt liabilities. The constrained optimisation problem is:

$\min _{\left\{C_{i}\right\}_{i=1,2, \ldots, n}}\left(\sum_{i} C_{i}\right)$ s.t.VaR $R_{z}^{\text {system }}\left(\left\{C_{i}\right\}_{i=1,2, \ldots, n}\right)=0$

The constraint in equation (3), $\operatorname{VaR}_{z}^{\text {system }}\left(\left\{C_{i}\right\}_{i=1,2, \ldots, n}\right)=0$, can also be expressed as $\operatorname{Pr}\left(\sum_{i}\left(A_{i}\left(C_{i}\right)\right)<\sum_{i}\left(D_{i}\right)\right)=1-z$. In other words, the policymaker tries to keep inefficiency (total capital) to a minimum subject to the banking system remaining solvent with a chosen target probability (the probability of system assets being below system liabilities being equal to $1-z) .^{3}$ The parameter $z$ reflects the trade-off between the systemic risk and efficiency objectives. For example, a high value of $z$ might be suitable if there is a relatively shallow trade-off between systemic risk and economic efficiency, ie in the case that equity capital is not materially more expensive than debt. ${ }^{4}$

Solving the policymaker's optimisation problem is complicated by the fact that the optimal level of capital in the banking system in aggregate and the optimal distribution of capital across banks are not separable. For example, consider a system of two banks. Each has the same fundamental uncertainty about asset value returns going forward, but bank $X$ starts with a much larger cushion of capital than bank $Y$. In this case, an extra $£ 1$ of capital given to bank $X$ has a smaller impact on its asset shortfall distribution than if it were given to bank $Y$. If, in addition, bank $X$ (idiosyncratically safe) has a large interbank asset against bank $Y$ (idiosyncratically risky), giving an extra $£ 1$ to bank $Y$ materially reduces the contingentdefault risk of bank $X$ - and, consequently, for the two-bank system in aggregate. Increasing the aggregate level of capital by $£ 1$ therefore has little impact on systemic risk unless it is given to bank $Y$.

To solve the policymaker's optimisation problem we use the following iterative procedure:

1. Determine the total level of system capital, holding fixed the relative shares of total capital for each bank, which achieves the chosen systemic risk constraint. This is done by taking each bank's observed capital levels and increasing (decreasing) total system capital, $\sum_{i} C_{i}$, if $\operatorname{VaR}_{z}^{\text {system }}\left(\left\{C_{i}\right\}_{i=1,2, \ldots, n}\right)=0$.

2. Adjust the share of total capital held by each bank, $\left\{C_{i}\right\}_{i=1,2, \ldots, n} \rightarrow\left\{\tilde{C}_{i}\right\}_{i=1,2, \ldots, n}$, such that $\operatorname{VaR}_{z}^{\text {system }}\left(\left\{\tilde{C}_{i}\right\}_{i=1,2, \ldots, n}\right)<0$. If this is possible, the allocation $\left\{\tilde{C}_{i}\right\}_{i=1,2, \ldots, n}$ must be

3 The assumption that the policymaker sets banks' capital requirements to limit the probability of system insolvency is conservative. Other assumptions could be made. For example, the policymaker could seek to limit the probability that the shortfall of assets below debt liabilities for the system does not exceed a particular (non-zero) value, to reflect the investment capital that may be available from investors prior to systemic default.

4 The extent to which equity capital is relatively more expensive than debt for banks remains an open question. For example, see Admati, DeMarzo, Hellwig and Pfleiderer (2010). 
superior to $\left\{C_{i}\right\}_{i=1,2, \ldots, n}$ because systemic risk is lowered for the same level of efficiency since $\sum_{i} \tilde{C}_{i}=\sum_{i} C_{i}$. The reallocation of capital across banks is done using simulated annealing to try to ensure that the global solution of the policymaker's constrained optimisation problem is obtained (see Cerny (1985)).

3. Reduce the level of system capital by a small amount $\varepsilon$, allocated pro-rata across banks, and perform the optimisation in step 2 again.

4. Repeat steps 2-3 until it is no longer possible to further reduce system capital and simultaneously achieve the policymaker's chosen tolerable level of systemic risk. This yields the minimum level of aggregate capital that can be allocated across banks and simultaneously meet the chosen systemic risk constraint.

\section{Model calibration}

The model is calibrated using UK data for the period $2004 \mathrm{H} 1$ to $2009 \mathrm{H} 1$. Banks' balance sheets are based on information from five major UK banks' published accounts. "Debt" is interpreted as total liabilities excluding large exposures to the other four banks, minus shareholders' funds excluding minority interests. "Large exposures" are defined as those exposures that exceed $10 \%$ of eligible capital, ${ }^{6}$ which UK banks must report to their supervisors. The interbank network is calibrated to these large exposures. ${ }^{7}$ When banks fail because of losses on interbank exposures (contagious default) rather than in response to the value of their non-bank assets (fundamental default), this paper assumes that assets are marked down by $10 \%$ from the level reached endogenously through the diffusion process in equation (1). It is assumed that banks have a weighted-average debt liability of one year, at which point their solvency is assessed. Banks' observed equity prices are used to estimate the contemporaneous expected return on banks' assets and the variance-covariance structure between banks' asset returns.

\section{Results}

Figure 2 shows the surcharges that would need to be added to banks' capital ratios to solve the policymaker's optimisation problem in the illustrative case $z=0.05$. They differ across banks because losses incurred by the rest of the system differ according to which bank(s) fails and because the probabilities of such losses crystallising vary. By design of the policymaker's optimisation problem, the corresponding distributions of system losses under the optimised configurations of bank capital shift to the level (see Figure 3 for the case for $2009 \mathrm{H} 1)$.

5 This is approximately equivalent to assuming that all Tier 1 capital is sufficiently loss-absorbing.

6 Defined as Tier 1 plus Tier 2 capital.

7 This relaxes the maximum entropy approach adopted in Elsinger et al (2006). 
Figure 2

\section{Systemic capital surcharges ${ }^{(a)}$}

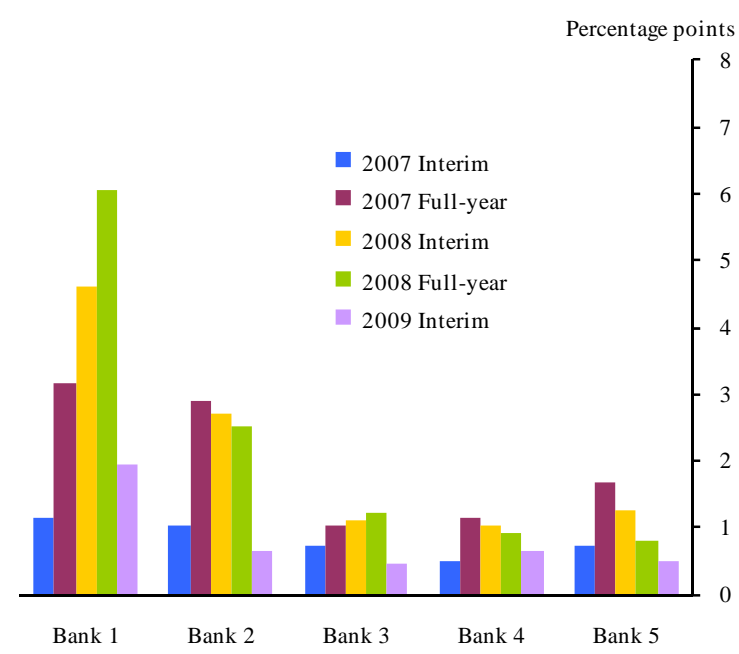

(a) Change in the ratio of capital to assets for each bank in the network following the optimisation in equation (3).
Figure 3

\section{System loss distributions pre- and post-optimisation $(2009 \mathrm{H1})^{(\mathrm{a})(\mathrm{b})(\mathrm{c})}$}

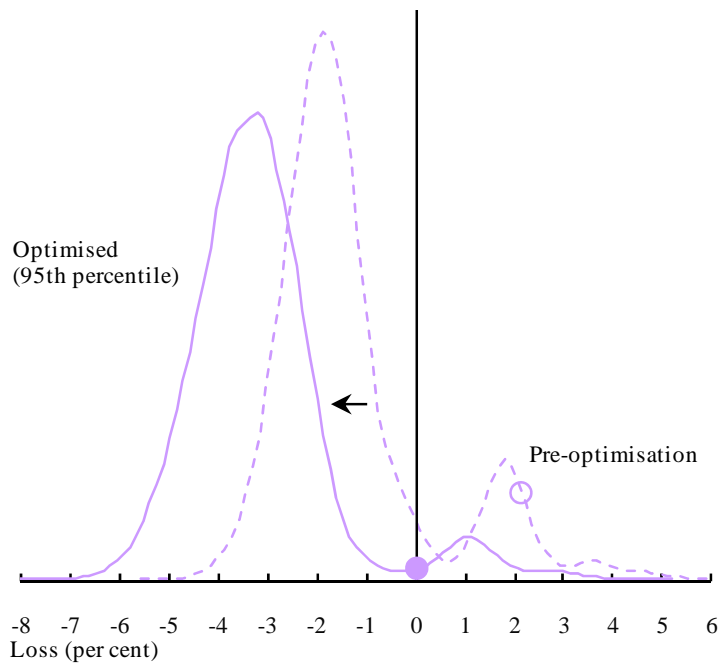

(a) Accounting for asset correlation and explicit interbank exposures between firms, assuming contagious default carries a deadweight cost of $10 \%$ of assets.

(b) Following the optimisation in equation (3). Circles show location of 95th percentile.

(c) Loss expressed as a fraction of system-wide debt liabilities.

Changing the characteristics of banks in ways that affect the impact of a bank failure on system losses changes the values of the capital surcharges. Figure 4 shows what happens if the size of one bank (bank 1 ) is increased. Systemic capital surcharges for bank 1 are higher than in the benchmark case to offset the larger impact its failure has on the rest of the system through the interbank network. This is actually sufficient, in a number of instances, to reduce systemic capital surcharges for the other banks in the network because there are fewer scenarios under which they experience interbank losses large enough to cause them to contagiously fail, which would otherwise further transmit and amplify losses. Figure 5 shows the marginal impact on systemic capital surcharges of doubling direct balance sheet exposures between banks. These results illustrate a robust-yet-fragile property of financial networks: the system as a whole can in some circumstances be made substantially more robust for a relatively small increase in aggregate capital, notwithstanding differences in capital surcharges across banks.

\section{Conclusions}

The financial crisis has led to calls for banks' capital requirements to be set, in part, to reflect the impact that their failure would have on the rest of the financial system. This paper has presented a potential system-wide risk management approach to informing the calibration of such systemic capital requirements. Using a calibrated model of a stylised banking system, the results in this paper illustrate that banks' systemic capital requirements are increasing in balance sheet size and in the value of their interbank obligations, other things being equal. 
Figure 4

\section{Systemic capital surcharges when} one bank doubles in size $e^{(a)(b)}$

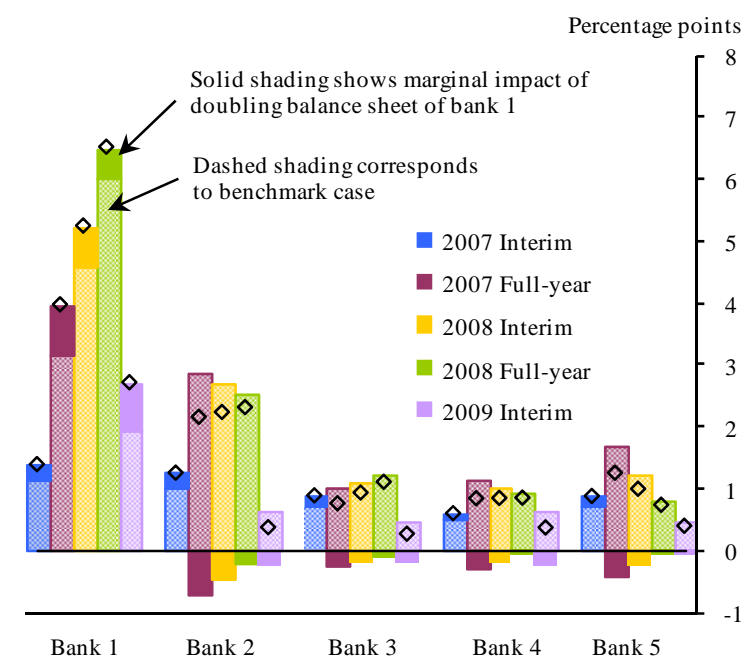

(a) Change in the ratio of capital to assets for each bank in the network following the optimisation in equation (3)

(b) Diamonds show total change in capital requirement.
Figure 5

\section{Systemic capital surcharges when} interconnections double in size $e^{(a)(b)}$

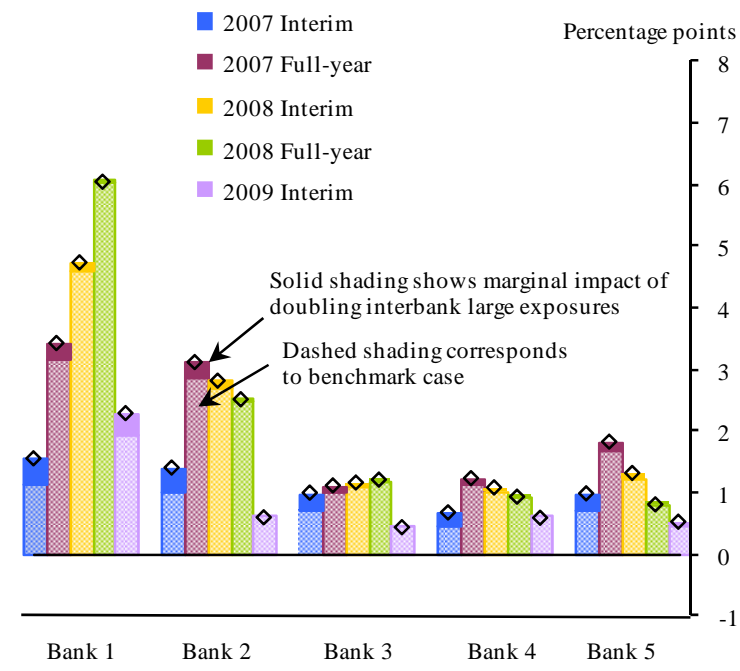

(a) Change in the ratio of capital to assets for each bank in the network following the optimisation in equation (3).

(b) Diamonds show total change in capital requirement.

\section{References}

Admati, A R, DeMarzo, P M, Hellwig, M F and Pfeiderer, P (2010), "Fallacies, irrelevant facts, and myths in the discussion of capital regulation: why bank equity is not expensive", mimeo.

Cerny, $V$ (1985): "A thermodynamical approach to the travelling salesman problem: an efficient simulation algorithm", Journal of Optimization Theory and Applications, vol 45, pp 41-51.

Eisenberg, L and Noe, T (2001): "Systemic risk in financial systems", Management Science, vol 47(2), pp 236-49.

Elsinger, H, A Lehar and M Summer (2006): "Using market information for banking system risk assessment", International Journal of Central Banking, no 1, vol 2, pp 137-66.

James, C (1991): "The losses realized in bank failures", Journal of Finance, vol 46(4), pp 1223-242.

Jensen, M (1986): "The agency costs of free cash flow: corporate finance and takeovers", American Economic Review, vol 76(2), pp 323-29.

Jensen, $M$ and W Meckling (1976): "The theory of the firm: managerial behavior, agency costs and ownership structure", Journal of Financial Economics, vol 3, pp 305-60.

Merton, R (1974): "On the pricing of corporate debt: the risk structure of interest rates", Journal of Finance, vol 29, pp 449-70.

Myers, S and Majluf, N (1984): "Corporate financing and investment decisions when firms have information that investors do not have", Journal of Financial Economics, vol 13, pp 187-221. 